\title{
Optimal dose of lisinopril for renoprotection in type 1 diabetic patients with diabetic nephropathy: a randomised crossover trial
}

\author{
K. J. Schjoedt • A. S. Astrup - F. Persson - E. Frandsen • \\ F. Boomsma • K. Rossing • L. Tarnow $・$ P. Rossing • \\ H.-H. Parving
}

Received: 26 May 2008 / Accepted: 18 September 2008 / Published online: 31 October 2008

(C) Springer-Verlag 2008

\begin{abstract}
Aims/hypothesis The purpose of this study was to evaluate the optimal renoprotective effect of ultrahigh doses of lisinopril, as reflected by short-term changes in urinary albumin excretion rate (UAER), in type 1 diabetic patients with diabetic nephropathy.

Methods At the Steno Diabetes Center, 49 type 1 diabetic patients with diabetic nephropathy completed this doublemasked randomised crossover trial consisting of an initial washout period followed by three treatment periods each lasting 2 months, where all patients received lisinopril 20,
\end{abstract}

Electronic supplementary material The online version of this article (doi:10.1007/s00125-008-1184-8) contains supplementary material, which is available to authorised users.

K. J. Schjoedt $(\triangle) \cdot$ A. S. Astrup · F. Persson $\cdot$ K. Rossing $\cdot$

L. Tarnow $\cdot$ P. Rossing

Steno Diabetes Center,

Niels Steensens Vej 1, NLC,

2820 Gentofte, Denmark

e-mail:kjos@steno.dk

E. Frandsen

Glostrup University Hospital,

Glostrup, Denmark

F. Boomsma

Erasmus MC,

Rotterdam, the Netherlands

H.-H. Parving

Rigshospitalet, Department of Medical Endocrinology,

University Hospital of Copenhagen,

Copenhagen, Denmark

H.-H. Parving

Faculty of Health Science, University of Aarhus,

Aarhus, Denmark
40 and $60 \mathrm{mg}$ once daily in randomised order in addition to slow-release furosemide. Allocation was concealed by sequentially numbered opaque sealed envelopes. UAER, $24 \mathrm{~h}$ ambulatory blood pressure (ABP) and estimated GFR were determined at baseline and after each treatment period. Results All 49 patients completed all three treatment periods. Baseline values were: UAER (geometric mean $[95 \% \mathrm{CI}]$ ) 362 (240-545) mg/24 h, 24 h ABP (mean [SD]) 142 (14)/74 (8) $\mathrm{mmHg}$ and estimated GFR 75 (29) $\mathrm{ml} \mathrm{min}^{-1} 1.73 \mathrm{~m}^{-2}$. Reductions in UAER from baseline were $63 \%, 71 \%$ and $70 \%$, respectively, with the increasing doses of lisinopril $(p<0.001)$. Compared with lisinopril $20 \mathrm{mg}$ there was a further reduction in UAER of $23 \%$ with lisinopril $40 \mathrm{mg}$ and $19 \%$ with $60 \mathrm{mg}, p<0.05$. ABP was reduced from baseline by $10 / 5,13 / 7$ and $12 / 7 \mathrm{mmHg}(p<0.001$ vs baseline, $p<0.05$ for diastolic ABP $20 \mathrm{vs} 40 \mathrm{mg}$, otherwise NS between doses). The difference in UAER between 20 and $40 \mathrm{mg}$ lisinopril was significant after adjustment for changes in ABP $(p<0.01)$. Two patients were excluded from the study because of an increase in plasma creatinine and one because of high BP; otherwise the study medication was well tolerated with few, mild, dose-independent adverse effects.

Conclusions/interpretation Lisinopril $40 \mathrm{mg}$ once daily is generally safe and offers additional reductions in BP and UAER in comparison with the currently recommended dose of $20 \mathrm{mg}$. Lisinopril $60 \mathrm{mg}$ offers no further beneficial effect.

\section{Trial registration: ClinicalTrials.gov NCT00118976}

Funding: This study was financed out of local funds and was not supported by the medical industry.

Keywords ACE inhibitor - Albuminuria . Diabetic nephropathy $\cdot$ Lisinopril · Optimal dose $\cdot$ Renoprotection . Type 1 diabetes 


\section{Abbreviations \\ ABP ambulatory blood pressure \\ ACEI ACE inhibitor \\ DN diabetic nephropathy \\ eGFR estimated glomerular filtration rate \\ ESRD end-stage renal disease \\ RAAS renin-angiotensin-aldosterone system \\ UAER urinary albumin excretion rate}

\section{Introduction}

Diabetic nephropathy (DN) is the most common single cause of end-stage renal disease (ESRD) in the western world and develops in approximately $30 \%$ of all type 1 diabetic patients [1]. Aggressive antihypertensive treatment with a special focus on blocking the renin-angiotensinaldosterone system (RAAS) has been shown to be particularly effective in improving outcome, and ACE inhibitors (ACEI) are now considered the first-line therapy in type 1 diabetic patients with DN.

Dose titration studies of ACEIs are traditionally conducted according to BP levels in essential hypertension $[2,3]$. The optimal BP-lowering dose is not, however, necessarily the same as the optimal dose for renoprotection. The aim of the current study was to determine the optimal renoprotective dose of lisinopril, as evaluated by short-term changes in albuminuria, in type 1 diabetic patients with DN.

\section{Methods}

Subjects From the outpatient clinic at Steno Diabetes Center, 63 type 1 diabetic patients with $\mathrm{DN}$ and hypertension $(>135 / 85 \mathrm{mmHg})$ were enrolled. Their DN was diagnosed clinically as previously described [4].

Main exclusion criteria were GFR $<30 \mathrm{ml} \mathrm{min}^{-1} 1.73 \mathrm{~m}^{-2}$, plasma potassium $>4.8 \mathrm{mmol} / \mathrm{l}$, severe hypertension $(>180 / 100)$, known renal artery stenosis, age $<18$ or $>70$ years, allergy to ACEI, chronic heart failure, myocardial infarction, unstable angina or coronary bypass grafting within the previous 3 months.

Design The study was a randomised, double-masked, crossover trial consisting of an initial 2 month washout period followed by three treatment periods, each lasting 2 months. During the washout period, all antihypertensive treatment was withdrawn and patients were put on slowrelease furosemide in individual but fixed doses (median [range] 60 [0-360] mg daily) to prevent fluid retention, BP becoming too high and hyperkalaemia during the study. Thereafter patients received lisinopril 20,40 or $60 \mathrm{mg}$ once daily in random order, with an initial 2 week run-in period when patients received lisinopril $20 \mathrm{mg}$.

At the end of each treatment period, the primary endpoint, urinary albumin excretion rate (UAER), and the secondary endpoints, $24 \mathrm{~h}$ ambulatory BP (ABP) and estimated GFR (eGFR), were determined, and blood samples were drawn to allow measurement of the components of the RAAS. For safety reasons, BP, plasma potassium, sodium and creatinine were determined 3 weeks after the beginning of each treatment period.

The study was performed according to the principles of the Declaration of Helsinki and was approved by the ethical committee of Copenhagen County. All patients gave their informed consent.

Laboratory procedures Urinary excretion of albumin was determined by turbidimetry in three consecutive $24 \mathrm{~h}$ urine collections completed immediately before the end of each treatment period (Hitachi 912 system; Roche Diagnostics, Mannheim, Germany).

Office BP and $24 \mathrm{~h}$ ABP were measured as described previously [4]. The eGFR was calculated using the reexpressed four-variable Modification of Diet in Renal Disease (MDRD) study equation [5].

From venous samples, haemoglobin, plasma potassium, sodium, creatinine and cholesterol concentrations and $\mathrm{HbA}_{1 \mathrm{c}}$ was measured using standard methods [4]. Blood samples for plasma renin activity, angiotensin I, angiotensin II, ACE-activity and aldosterone concentrations were taken after $30 \mathrm{~min}$ of supine rest.

Statistical analysis

Normally distributed variables are expressed as means with either SD or SE in parentheses. Non-normally distributed variables were logarithmically transformed before statistical analysis and are given as geometric means (95\% CI). Comparisons of UAER, ABP and eGFR between each treatment period were performed using linear mixed models.

Based on a previously calculated SD (log scale 0.1771) of the mean difference in UAER, a sample-size calculation showed a necessary minimum of 50 patients to detect a $15 \%$ difference in change in UAER between any two dose levels $(\alpha=0.05, \beta=0.80)$.

A value of $p<0.05$ was considered significant (two-tailed test). Data were evaluated using SPSS version 14.0 (SPSS, Chicago, IL, USA).

\section{Results}

A total of 63 patients gave their informed consent to participate in the study. Seven patients were excluded 
Table 1 Baseline characteristics in 49 type 1 diabetic patients with $\mathrm{DN}$, after a 2 month washout period where all antihypertensive medication, except for slow-release furosemide, was withdrawn

\begin{tabular}{|c|c|}
\hline Characteristic & Value \\
\hline Sex (female/male) $(n)$ & $16 / 33$ \\
\hline Age (years) & $49(10)$ \\
\hline Diabetes duration (years) & $33(10)$ \\
\hline $24 \mathrm{~h} \mathrm{ABP}(\mathrm{mmHg})$ & $142(14) / 74(8)$ \\
\hline $\mathrm{UAER}^{\mathrm{a}}(\mathrm{mg} / 24 \mathrm{~h})$ & $362(240-545)$ \\
\hline Estimated GFR $\left(\mathrm{ml} \mathrm{min}{ }^{-1} 1.73 \mathrm{~m}^{-2}\right)$ & $75(29)$ \\
\hline
\end{tabular}

Data are given mean (SD) and a geometric mean $(95 \% \mathrm{CI})$

during the washout period because of high BP. Fifty-six patients were randomised, but two patients were excluded because of a reversible increase in creatinine (one on lisinopril $20 \mathrm{mg}$ and one on lisinopril $60 \mathrm{mg}$ ) and one because of high BP (lisinopril $60 \mathrm{mg}$ ). Four patients withdrew consent before completing the study because of minor complaints (see Electronic supplementary material [ESM] Fig. 1 for details of patient-flow and adverse events). Three patients had a transient increase in plasma potassium after 2 months of lisinopril $60 \mathrm{mg}$, which was reversed by standard treatment. No patients had plasma potassium $>5.5 \mathrm{mmol} / \mathrm{l}$ on lisinopril 20 or $40 \mathrm{mg}$. No other adverse events were reported during the study.

Results are given for 49 patients who completed the study. Baseline variables are given in Table 1.

All doses of lisinopril significantly reduced UAER, ABP and eGFR from baseline (Table 2).

Reductions in UAER, given as mean difference $(95 \%$ CI) from baseline were $63 \%(55-69), 71 \%(66-76)$ and
$70 \%$ (64-75) with increasing doses of lisinopril $(p<0.001$; see ESM Fig. 2). Compared with the standard dose, i.e. lisinopril $20 \mathrm{mg}$, there was a significant further reduction in UAER with lisinopril $40 \mathrm{mg}$ of $23 \%(8-35)$ and $60 \mathrm{mg}$ $19 \%(3-31) p<0.05$. There was no difference in UAER between lisinopril $40 \mathrm{mg}$ and $60 \mathrm{mg}$.

The reduction in ABP did not differ significantly between doses (except $p<0.05$ for diastolic ABP $20 \mathrm{mg}$ vs $40 \mathrm{mg}$ ). The effect on BP lasted through $24 \mathrm{~h}$, with optimal effect from lisinopril $40 \mathrm{mg}$, as shown in ESM Fig. 2. Laboratory data are specified in Table 2.

Patients who responded better on increasing doses of lisinopril could not be predicted by levels of UAER, ABP, eGFR or plasma renin activity at baseline or during treatment with lisinopril $20 \mathrm{mg}$. There was a significant correlation between $\triangle \mathrm{UAER}$ and $\triangle \mathrm{BP}$ (changes from 20 to $40 \mathrm{mg}, R=0.49, p<0.001$ ), corresponding to a $2.8 \%$ reduction in UAER for every $1 \mathrm{mmHg}$ reduction in systolic BP. After adjustment for changes in $24 \mathrm{~h}$ ABP, the difference in UAER between $20 \mathrm{mg}$ and $40 \mathrm{mg}$ lisinopril was still significant $(p<0.01)$.

\section{Discussion}

We evaluated the optimal renoprotective dose of the ACEI lisinopril in type 1 diabetic patients with DN. The overall reduction in albuminuria and BP was most pronounced during treatment with lisinopril $40 \mathrm{mg}$ compared with the previously recommended dose of $20 \mathrm{mg}$ daily. Our study shows that increasing the dose of lisinopril to $60 \mathrm{mg}$ does not reduce albuminuria or BP further. The beneficial effects

Table 2 Laboratory data during treatment with lisinopril 20, 40 and $60 \mathrm{mg}$ in random order compared with baseline in 49 type 1 diabetic patients with DN

\begin{tabular}{|c|c|c|c|c|}
\hline \multirow[t]{2}{*}{ Characteristic } & \multirow[t]{2}{*}{ Baseline } & \multicolumn{3}{|l|}{ Lisinopril (mg) } \\
\hline & & 20 & 40 & 60 \\
\hline $\mathrm{UAER}^{\mathrm{a}}(\mathrm{mg} / 24 \mathrm{~h})$ & $362(240-545)$ & $121(85-172)^{\mathrm{b}}$ & $100(68-147)^{\mathrm{b}, \mathrm{c}}$ & $103(69-154)^{\mathrm{b}, \mathrm{c}}$ \\
\hline $24 \mathrm{~h} \mathrm{ABP}(\mathrm{mmHg})$ & $142(2) / 74(1)$ & $131(2)^{\mathrm{b}} / 67(1)^{\mathrm{b}}$ & $128(2)^{\mathrm{b}} / 66(1)^{\mathrm{b}, \mathrm{c}}$ & $130(2)^{\mathrm{b}} / 66(1)^{\mathrm{b}}$ \\
\hline Estimated GFR $\left(\mathrm{ml} \mathrm{min}{ }^{-1} 1.73 \mathrm{~m}^{-2}\right)$ & $75(4)$ & $69(4)^{b}$ & $68(4)^{\mathrm{b}}$ & $67(4)^{\mathrm{b}}$ \\
\hline P-potassium $(\mathrm{mmol} / \mathrm{l})$ & $3.9(0.1)$ & $4.3(0.1)^{\mathrm{b}}$ & $4.4(0.1)^{\mathrm{b}}$ & $4.4(0.1)^{\mathrm{b}}$ \\
\hline $\mathrm{HbA}_{1 \mathrm{c}}(\%)$ & $8.6(0.1)$ & $8.7(0.2)$ & $8.8(0.2)$ & $8.9(0.1)^{\mathrm{b}}$ \\
\hline B-Haemoglobin (mmol/l) & $8.3(0.1)$ & $8.0(0.1)^{\mathrm{b}}$ & $7.8(0.1)^{\mathrm{b}, \mathrm{c}}$ & $7.9(0.1)^{\mathrm{b}, \mathrm{c}}$ \\
\hline P-total cholesterol $(\mathrm{mmol} / \mathrm{l})$ & $4.5(0.1)$ & $4.2(0.1)^{\mathrm{b}}$ & $4.1(0.1)^{\mathrm{b}}$ & $4.2(0.1)^{\mathrm{b}}$ \\
\hline P-renin activity (ng angiotensin $\mathrm{I} \mathrm{ml}^{-1} \mathrm{~h}^{-1}$ ) & $6(5-7)$ & $22(17-31)^{\mathrm{b}}$ & $26(20-34)^{\mathrm{b}}$ & $35(26-47)^{\mathrm{b}, \mathrm{d}}$ \\
\hline P-ACE activity (U) & $51(44-58)$ & $4.4(3.5-5.6)^{\mathrm{b}}$ & $3.0(2.3-3.8)^{\mathrm{b}, \mathrm{c}}$ & $2.7(2.3-3.2)^{\mathrm{b}, \mathrm{c}}$ \\
\hline P-angiotensin I (pmol/1) & $25(21-29)$ & $130(95-179)^{\mathrm{b}}$ & $134(102-177)^{\mathrm{b}}$ & $192(142-260)^{\mathrm{b}, \mathrm{c}}$ \\
\hline P-angiotensin II (pmol/l) & $11(8-14)$ & $4.1(2.9-5.9)^{\mathrm{b}}$ & $2.9(1.9-4.3)^{\mathrm{b}, \mathrm{c}}$ & $3.2(2.2-4.6)^{\mathrm{b}}$ \\
\hline P-aldosterone $(\mathrm{pg} / \mathrm{ml})$ & $66(51-86)$ & $26(17-41)^{\mathrm{b}}$ & $22(15-32)^{\mathrm{b}}$ & $19(12-30)^{\mathrm{b}}$ \\
\hline
\end{tabular}

Data are mean (SE) or ${ }^{\text {a }}$ geometric mean $(95 \% \mathrm{CI})$

${ }^{\mathrm{b}} p<0.05$ vs baseline, ${ }^{\mathrm{c}} p<0.05 \mathrm{vs} 20 \mathrm{mg},{ }^{\mathrm{d}} p<0.05 \mathrm{vs} 20 \mathrm{mg}$ and $40 \mathrm{mg}$. Friedman test for several related samples was used followed by paired samples $t$ test if significant

B, blood; P, plasma 
of lisinopril $40 \mathrm{mg}$ were obtained without any additional adverse effects compared with $20 \mathrm{mg}$.

Our study has the strength of being a randomised, double-masked crossover trial conducted in one centre, ensuring a uniform setting and uniform treatment of patients. Long-term evaluation of the efficacy and safety of high dosing of lisinopril has not been performed and should be conducted in a controlled manner in the future.

The importance of finding the optimal renoprotective dose was previously acknowledged in other studies evaluating the optimal dose of angiotensin II receptor blockers in type 2 diabetic patients with micro- or macroalbuminuria $[6,7]$. Although BP reductions were similar, further reduction in UAER was achieved by increasing dosage of angiotensin II receptor blocker above the recommended dose $[6,7]$. Anti-proteinuric effects are associated with reno- and cardioprotective long-term effects.

Increasing RAAS blockade without further clinical benefit is costly and may be associated with more adverse events and even risk of renal impairment, as recently suggested by the ONTARGET study [8]. Detailed information from ONTARGET about albuminuria and causes of renal endpoints including dialysis, is so far lacking but may provide important information about the benefit or harm of aggressive RAAS blockade on renal disease, including DN.

Previous dose titration studies with lisinopril have been conducted in (1) non-diabetic patients with essential hypertension, using BP reductions as the main outcome $[2,3]$; and (2) patients with non-diabetic nephropathies [9, 10]. Lisinopril $40 \mathrm{mg}$ was shown to lower albuminuria and BP more effectively than lisinopril $20 \mathrm{mg}$. Higher doses have only been tested in essential hypertension studies. Overall, previous studies have provided evidence that suggests a better BP reduction with lisinopril doses higher than $20 \mathrm{mg}$ daily and more efficient albuminuria lowering with lisinopril $40 \mathrm{mg}$ daily (no higher doses tested); however, the recommended doses have been $20-40 \mathrm{mg}$ lisinopril for hypertension and 10-20 mg for 'renal complications caused by diabetes'.

Two patients had an increase in creatinine which was normalised after withdrawal of the study medication. This illustrates that it is important to evaluate kidney function during treatment with ACEI. In particular, this is important with ACEIs that are mainly (or exclusively) eliminated through the kidney, such as lisinopril. No patients had plasma potassium above $5.5 \mathrm{mmol} / \mathrm{l}$ on lisinopril $40 \mathrm{mg}$.

In conclusion, lisinopril $40 \mathrm{mg}$ once daily was safe in our patients with $\mathrm{DN}$ and induced a further reduction in albuminuria and BP compared with the currently recommended dose of lisinopril $20 \mathrm{mg}$. Increasing the dose to $60 \mathrm{mg}$ daily offered no beneficial effect on albuminuria or BP.

Acknowledgements We would like to thank B. R. Jensen, T. R. Juhl, B. V. Hansen, U. M. Smidt and L. Pietraszek for their help with collecting the data and B. Blaaholm for excellent nursing guidance of the patients. This study was not supported by the medical industry.

Duality of interest The authors declare that there is no duality of interest associated with this manuscript.

\section{References}

1. Parving H-H, Mauer M, Ritz E (2004) Diabetic nephropathy. In: Brenner BM (ed) The kidney, 7th edn. Saunders, Philadelphia, pp 1777-1818

2. Cirillo VJ, Gomez HJ, Salonen J et al (1988) Lisinopril: dosepeak effect relationship in essential hypertension. $\mathrm{Br} \mathrm{J}$ Clin Pharmacol 25:533-538

3. Gomez HJ, Cirillo VJ, Sromovsky JA et al (1989) Lisinopril dose-response relationship in essential hypertension. Br J Clin Pharmacol 28:415-420

4. Schjoedt KJ, Rossing K, Juhl TR et al (2006) Beneficial impact of spironolactone on nephrotic range albuminuria in diabetic nephropathy. Kidney Int 70:536-542

5. Levey AS, Coresh J, Greene T et al (2006) Using standardized serum creatinine values in the modification of diet in renal disease study equation for estimating glomerular filtration rate. Ann Intern Med 145:247-254

6. Rossing K, Schjoedt KJ, Jensen BR, Boomsma F, Parving H-H (2005) Enhanced renoprotective effects of ultrahigh doses of irbesartan in patients with type 2 diabetes and microalbuminuria. Kidney Int 68:1190-1198

7. Hollenberg NK, Parving H-H, Viberti G et al (2007) Albuminuria response to very high-dose valsartan in type 2 diabetes mellitus. J Hypertens 25:1921-1926

8. Yusuf S, Teo KK, Pogue J et al (2008) Telmisartan, ramipril, or both in patients at high risk for vascular events. N Engl J Med 358:1547-1559

9. Laverman GD, Navis G, Henning RH, de Jong PE, de Zeeuw D (2002) Dual renin-angiotensin system blockade at optimal doses for proteinuria. Kidney Int 62:1020-1025

10. Ruggenenti P, Mise N, Pisoni R et al (2003) Diverse effects of increasing lisinopril doses on lipid abnormalities in chronic nephropathies. Circulation 107:586-592 